\title{
ISOLATION AND DETECTION OF HELICOBACTER PYLORI FROM PATIENTS SUFFERING FROM PEPTIC ULCER USING BIOCHEMICAL TESTS AND MOLECULAR TECHNIQUES
}

\author{
${ }^{1}$ Ruba S. Abu-Sbeih, ${ }^{2}$ Azmi D. Hawari, ${ }^{3}$ Dhia S. Hassawi and ${ }^{4}$ Hala I. Al-Daghistani \\ ${ }^{1}$ Department of Biotechnology, \\ ${ }^{2}$ Department of Nutrition and Food Processing, \\ Faculty of Agricultural Technology, Al-Balqa' Applied University, Al-Salt, 19117 Jordan \\ ${ }^{3}$ Department of Biology, College Sciences, Al-Anbar University, Al-Anbar, Iraq \\ ${ }^{4}$ Al-Salt College for Humanitarian Sciences, Al-Balqa' Applied University, Al-Salt, 19117 Jordan
}

Received 2014-01-27; Revised 2014-03-04; Accepted 2014-03-28

\begin{abstract}
Helicobacter pylori is the causative agent of most cases of gastritis. There is no established gold standard for the diagnosis of $H$. pylori infection. A reliable diagnosis is crucial to confirm that eradication therapy has been successful. Eighty gastric biopsy and blood samples were obtained from fasting Jordanian patients with Esophago-Gastro-Doudenoscopy (EGD). Several diagnosis tests for $H$. pylori infections were used and compared including: Culture, microscopic examination, histopathology, Rapid Urease Test (RUT), serology, biochemical tests, antibiotic susceptibility test and molecular method. Forty two patients were considered $H$. pylori positive in both histopathology examination and RUT test. On the other hand, 57 patient were detected to have anti-IgA, IgG H. pylori antibody positive by ELISA test. Ten patients had equivocal results but not in both tests. A total of 19 biopsy samples were positive for $H$. pylori according to culture test. This result was confirmed by endoscopic examination, urease, catalase and oxidase. A high percentages of resistance to vancomycin, polymyxin B and amoxicillin was observed (100, 100 and $94.7 \%$, respectively) with various degree of sensitivity to all of the first line of antibiotics. Molecular technique (PCR) was used to detect CagA gene which appeared positive in 14 patients. We conclude that the histopathology and RUT tests are reliable invasive diagnosis for $H$. pylori. However, culture test appear to be the most important (if the therapy failed) to detect antibiotic susceptibility to H. pylori strains.
\end{abstract}

Keywords: Helicobacter Pylori, Biochemical Diagnosis, ELISA, Antibiotic Sensitivity, Molecular Detection

\section{INTRODUCTION}

The discovery of Helicobacter pylori in 1982 was the starting point of a revolution concerning the concepts and management of gastroduodenal diseases (Megraud and Lehours, 2007). Helicobacter pylori, originally classified as Campylobacter pylori (Al-Sulami et al., 2010). Selfingestion experiments and experiments with volunteers demonstrated that these bacteria can colonize the human stomach, thereby inducing inflammation of the gastric mucosa (Morris et al., 1991). These initial data stimulated for further study, which showed that gastric colonization with $H$. pylori can lead to upper gastrointestinal disorders, such as chronic gastritis, peptic ulcer disease, gastric mucosaassociated lymphoid tissue lymphoma and gastric cancer. The severity of the inflammation is likely to underlie $H$. pylori-related diseases (Abdalsadeg et al., 2012). Although most individuals do not develop adverse clinical consequences from $H$. pylori colonization, between 10 and $15 \%$ will experience some form of symptomatology Corresponding Author: Ruba S. Abu-Sbeih, Department of Biotechnology, Faculty of Agricultural Technology, Al-Balqa' Applied University, Al-Salt, 19117 Jordan 
and the clinical result of the infection will be determined by complex interactions between host and bacterial factors. While the host factors remain unknown, the identification of specific bacterial factors is continuously advancing (Cogo et al., 2011).

H. pylori is a gram negative bacterium typically appearing as a curved rod or short spiral. It is believed to be one of the more common pathogenic infections of man, with prevalence rates reaching $30-60 \%$ in developed countries, depending on age and socioeconomic status (Vinette et al., 2002). The mode of transmission and other aspects of the epidemiology of $H$. pylori infection still remain unclear (Tiwari et al., 2005). Several virulence factors that aid $H$. pylori in colonization of the host and contribute to disease development have been identified by a variety of methods. One of these factors is the urease enzyme that $H$. pylori needs to survive in the low-pH gastric lumen as it makes its way to the gastric mucosa, which has a more neutral $\mathrm{pH}$ (Montecucco and Rappuoli, 2001). H. pylori also requires several motility and chemotaxis genes for colonization, presumably so that it can locate and move to its preferred site of infection and remain there (Ottemann and Lowenthal, 2002).

Diagnosing $H$. pylori infection is sometimes difficult (Tiwari et al., 2005). Accurate diagnosis is essential for the effective treatment and management of infections caused by this organism (Abdalsadeg et al., 2012). $H$. pylori infection can be diagnosed by invasive techniques (endoscopy with biopsies for histology, culture and a rapid urease test) (Vaira and Vakil, 2001). Culture and identifying $H$. pylori in gastric biopsy require experience and dexterity, as identification and culturing are sometimes difficult. Microscopy and rapid urease test can be highly specific if strictly performed, but they are based on biopsy specimens and thus are theoretically prone to sampling error, as in the case of culture (Yoshida et al., 1998). Since invasive methods are expensive, less invasive methods such as serological examination of blood and the urea breath test have become more popular (Zagari et al., 1999). However, positive results by blood serology do not necessarily allow delineation of active $H$. pylori infection. Urea breath tests require expensive specialized equipment and reagents and sometimes become apparently positive in culture negative patients (Bazzoli et al., 1997).

Molecular methods like Polymerase Chain Reaction (PCR) have been used extensively for the diagnosis of $H$. pylori from gastric biopsy specimens, saliva, faeces and archival specimens, as well as for detecting clarithromycin resistance (Zsikla et al., 2006). PCR yields information on the presence of potential virulence markers in the strain, which might have implications for the development of severe disease or efficacy of eradication (Ricci et al., 2007). Different primers have been utilized and some have been developed into commercial kits. Different loci have been used as the target for the amplification: $16 \mathrm{~S}$ rRNA; A-B-and Curease; flaA; CagA; vacA and heat-shock protein (hsp). Real-time results can be obtained using light-cycle technology (Ricci et al., 2007).

The present study was therefore carried out to test some feasible non-invasive and invasive methods for the rapid diagnosis of $H$. pylori among infected patients suffering from various gastric maladies using biochemical tests and molecular techniques.

\section{MATERIALS AND METHODS}

\subsection{Collection of Samples}

\subsubsection{Biopsy Samples}

A total of 80 biopsy patients (30 males and 50 females) aged from 18-81 years were collected from two different local hospitals. The patients were suffering from dyspepsia and advised by the doctors to have clinical indications for an endoscopy in the gastrointestinal clinic of the hospitals. All the patients with dyspepsia undergoing endoscopy were asked to fill the inclusion questioner. Biopsies of gastric tissue were collected from the corpus or the antrum or corpus and antrum of the patient's stomach. Three biopsies were taken from each patient. Then, specimens were sent for histopathologic study, gram staining, sensitivity and rapid urease test.

The taken biopsies were classified according to the performed test. The biopsy used for histopathology examination was transported to the histopathology laboratory with $10 \%$ buffered formalin for at least $24 \mathrm{~h}$. The biopsy used for culture was transported to the laboratory with 2-2.5 $\mathrm{mL}^{-1}$ Tryptical Soy Broth (TSB) as a transport medium. The biopsy which used for RUT was tested immediately at the department of gastroenterology and the result examined within $1 \mathrm{~h}$.

\subsubsection{Blood Samples}

Blood samples (3-5 $\mathrm{mL}^{-1}$ ) were taken before each patient's enter to endoscopic unit and before initiation of any therapy. The blood was kept at room temperature for $1 \mathrm{~h}$; the clot was removed by centrifuging at 1,000 $2,000 x \mathrm{~g}$ for $10 \mathrm{~min}$ in the centrifuge. The resulting supernatant was designated serum. Following centrifugation, the samples were immediately transferred into a clean, sterile eppendorf tube using a Pasteur pipette. The samples were maintained at $2-8^{\circ} \mathrm{C}$ while handling. Then the serum was stored at $-20^{\circ} \mathrm{C}$ until using for Enzyme-Linked Immunosorbent Assay (ELISA) test. 
Samples that are hemolyzed, icteric or lipemic were excluded from the study.

\subsection{Histopathologic Examination}

This test was performed by the laboratory technical in the hospital and read by the doctor following standard procedure (Dixon et al., 1996). The gastric biopsies were fixed in $10 \%$ buffered formalin for at least $24 \mathrm{~h}$ and then embedded in paraffin. In each case, three sections of the tissues were cut at 0.3 micron, de-paraffinized and hydrated in descending grades of alcohol, cut in sequential 4- $\mu \mathrm{m}$ sections. One section was stained with routine haematoxylin and eosin stain. The second section was stained with modified Giemsa stain to demonstrate the presence of $H$. pylori. The $H$. pylori were identified as curved rods on the luminal surface of the gastric epithelial cells. The third section was stained with alcian blue/Periodic Acid Schiff's stain to demonstrate the presence of intestinal metaplasia.

\subsection{Biochemical Tests}

\subsubsection{Culture of $\boldsymbol{H}$. Pylori from Biopsy Sample}

The antral biopsy specimens were transported to the microbiology laboratory immediately within less than one hour in 2-2.5 mL tryptic soy broth as a transport medium. The biopsy specimens were first ground in a sterile mortar with the aid of a sterile fine glass rod until the formation of homogenate. The biopsies were inoculated at Columbia Agar (CA) plates supplemented with $8 \%$ sheep blood, vancomycin $\left(10 \mathrm{mg} \mathrm{mL}^{-1}\right)$, trimethoprim lactate $\left(5 \mathrm{mg} \mathrm{L}{ }^{-1}\right)$, amphoteracin-B $(5 \mathrm{mg}$ $\left.\mathrm{mL}^{-1}\right)$, polymixin-B (2500 units $\left.\mathrm{mL}^{-1}\right)$ and incubated in a microaerobic atmosphere (10 $\mathrm{CO} 2,85 \mathrm{~N} 2,5 \% \mathrm{O} 2)$ (Sigma, Aldrich) at $37^{\circ} \mathrm{C}$ for 5-7 days. The bacteria were identified as $H$. pylori by Gram staining, colony morphology, positive oxidase, catalase and urease reactions (Balows et al., 1991). Bacteria were sub-cultured using the same conditions into two different media: Columbia agar with supplements and brain heart infusion broth.

\subsubsection{Rapid Urease Test}

Biopsy specimens were tested for urease activity by using the "HelicotecUT®Plus" test.

\subsubsection{Urease Test}

The urease test was applied according to MacFaddin (2000). The pure isolates were inoculated heavily on the entire surface of urea agar and stab with loop wire. The tubes were inoculated at $37^{\circ} \mathrm{C}$ in the incubator. The formation of purple color was examined after $4 \mathrm{~h}$.

\subsubsection{Oxidase Test}

The isolates were tested for oxidase activity by using oxidase test strip.

\subsubsection{Catalase Test}

The isolates were tested for catalase activity by using slide (drop) method in which the sterile wire loop is stacked on the surface of the pure colony and transferred to a microscope slide and one or two drop of $3 \%$ $\mathrm{H} 2 \mathrm{O} 2$ were added onto the organism on the slide and observed for immediate oxygen bubble formation.

\subsection{Atibiotic Susceptibility Test}

The used antibiotics were: Clarithromycin $\left(15 \mu \mathrm{g}^{-1}\right)$, tetracycline $\left(10 \mu \mathrm{g}^{-1}\right)$, amoxicillin $(25 \mathrm{mcg})$, polymyxin B300 UNITs, vancomycin $\left(5 \mu^{-1}\right)$, trimethoprim (2.5), kanamycin (30mcg) and rifampin (5mcg) (MASTDISCS $^{\mathrm{TM}}$, Bioanalyse $\left.{ }^{\circledR}\right)$. Muller Hinton (MH) (Oxoid, England) containing 10\% human blood and $H$. pylori-selective supplement (Oxoid, England) was used for the disk diffusion (Kirby-Bauer) technique. Using the published CLSI guidelines, the susceptibility, or resistance of the $H$. pylori to each antibiotic was determined disk diffusion method for Antimicrobial Susceptibility Testing (EUCAST).

\subsection{Serology Test}

\subsubsection{Serum Enzyme-Linked Immunosorbent Assay Testing (Elisa)}

Serum samples were tested for anti- $H$ pylori antibodies $\mathrm{IgA} / \mathrm{IgG}$ by using the NovaLisa ${ }^{\mathrm{TM}}$ Enzyme-Linked ImmunoSorbent Assay (ELISA) kit (NovaTec Immundiagnostica $\mathrm{GmbH}$ ) according to manufacturer directions. Value of $<15$ Nephelometric Turbidity Units (NTU)/mL were negative, $>20 \mathrm{NTU} / \mathrm{mL}$ were positive, between 15 and $20 \mathrm{NTU} / \mathrm{mL}$ were equivocal.

\subsection{Molecular Techniques}

\subsubsection{DNA Extraction from Biopsy Samples}

Specimens of gastric biopsy were collected in a sterile container containing digestion buffer $(100 \mathrm{mM}$ $\mathrm{NaCl}, 10 \mathrm{mM}$ Tris- $\mathrm{HCl}$ (pH 8.0) 0.5\% SDS) and frozen at $-70^{\circ} \mathrm{C}$ until using. Genomic DNA was isolated from all samples by the Cetyltrimethyl Ammonium Bromide (CTAB) method with an additional initial digestion with lysozyme buffer and incubation with the buffer at $37^{\circ} \mathrm{C}$ for $24 \mathrm{~h}$, then according to the standard protocol. Extensive care was taken to avoid contamination during all steps of collection and preparation of the samples. 


\subsubsection{PCR Amplification}

Two oligonucleotide primers designated $\operatorname{CagA-F}\left(5^{\prime}-\right.$ AATACACCAACGCCTCCAAG-3') and $\operatorname{CagA-R}\left(5^{\prime}\right.$ TTGTTGCCGCTTGCTCTC-3') was used. The amplified product of these two primers with DNAs was a $395 \mathrm{bp}$ fragment. The template DNA $\left[2 \mu \mathrm{L}^{-1}\right]$ was added to $18 \mu \mathrm{L}^{-1}$ of the reaction mixture containing $1 \mathrm{X}$ PCR buffer [50 mM KCl, $10 \mathrm{mM}$ Tris- $\mathrm{HCl}(\mathrm{pH} 8.3), 1.5 \%$ (v/v) Triton X-100], $1.5 \mathrm{mM} \quad \mathrm{MgCl} 2,200 \mathrm{uM}$ concentrations of each dNTPs, 10 pmol of each primer and $1 \mathrm{U}$ of $\mathrm{Taq}$ polymerase. PCR amplification was performed according to the following program: Initial denaturation at $96^{\circ} \mathrm{C}$ for 5 min 40 cycles with each cycle consisting of $94^{\circ} \mathrm{C}$ for $1 \mathrm{~min}, 62^{\circ} \mathrm{C}$ for $1 \mathrm{~min}$ and $72^{\circ} \mathrm{C}$ for $2 \mathrm{~min}$. The final cycle included a $10 \mathrm{~min}$ extension step to ensure full extension of the PCR products. In each batch of PCR assays the negative control consisted of all the reagents of the master mix except the template DNA. The PCR-amplified products were analyzed by agarose gel electrophoresis. The gel was stained with ethidium bromide and examined under UV transilluminator for the presence of the amplified DNA.

\subsection{Statistical Analysis}

Standard method was used to calculate sensitivity and specificity for the result of diagnostic test. Sensitivity relates to the test's ability to identify positive results. The sensitivity of a test is the proportion of people that are known to have the disease who test positive for it. This can also be written as:

$$
\begin{aligned}
& \text { Sensitivity }=\frac{\text { number of true positive }}{\text { true positive }+ \text { false negative }} \\
& \text { Specificity }=\frac{\text { number of true negative }}{\text { true negative }+ \text { false positive }}
\end{aligned}
$$

\section{RESULTS}

\subsection{Data Collection Analysis}

A total of 240 biopsy samples were collected from 80 Jordanian patients. The objectives of this study were described for the patients and they agreed to be in the population of the study. They filled the required case history data which included civilian information about the patients (sex, age,), the symptoms they suffering from (epigastric pain, nausea, vomiting....) and their medical history (other diseases and medications).

The results of the case history data indicated that there were $38.75 \%$ (31 out of 80 ) males and $61.25 \%$ (49 out of 80 ) females with age range 18-81 years and mean age 42.55 years. $96.25 \%$ (77 out of 80 ) of the patients were not on any medications while $3.75 \%$ (3 out of 80 ) used aspirin, famodar, NAISD before presentation to the outpatients, but not in a regular way. Forty four patients were suffering from epigastric pain for 6-12 months and 67 suffering from heartburn and 55 suffering from the symptoms after eating.

\subsection{Serum Enzyme-Linked Immunosorbent Assay Test (ELISA)}

The 80 patients consented to be randomly tested against H. pylori serum antibody (IgG and $\operatorname{IgA})$. Anti- H. pylori IgG antibodies were present in $56(70 \%)$, while anti- $H$. pylori $\operatorname{IgA}$ antibodies present in $47(58.75 \%$ ) (Table 1). The test depends on the optical density for the formed colored because of interaction between antibodies (if they present in serum) with the substrate solution form yellow color. The results of the absorbance and concentrations of AntiH. pylori, IgG and IgA antibodies for the 80 samples are presented as standard curve in (Fig. 1).

\subsection{Histopathologic and Endoscopic Examination with RUT Test}

To confirm the infection of 80 patients with $H$. pylori, histopathology and endoscopy examination and RUT test were used. The result indicated that 43 (53.75\%) patients were RUT positive and 37 (46.25\%) were RUT negative. Forty (50\%) were histology positive and $40(50 \%)$ were negative (Fig. 2). The main endoscopic findings were gastritis 52 (65\%), gastroesophageal reflux disease $13(16.25 \%)$, duodenitis $8(10 \%)$ and the ulceration $10(12.5 \%)$ (Table 2).

Table 1. Anti- H. pylori antibody IgG and IgA ELISA test $(\mathrm{n}=80)$

\begin{tabular}{lll}
\hline & Anti- H. pylori & Anti- H. pylori \\
Samples & $\operatorname{IgA}(\%)$ & $\operatorname{IgG}(\%)$ \\
\hline Positive & $47(58.75)$ & $56(70)$ \\
Negative & $33(41.25)$ & $24(30)$ \\
\hline
\end{tabular}

Table 2. Rapid Urease Test (RUT), endoscopic and histopathology results of the patients $(n=80)$

\begin{tabular}{lll}
\hline & The test & Number of patients $(\%)$ \\
\hline $\begin{array}{l}\text { Endoscopic } \\
\text { finding }\end{array}$ & Gastritis & $52(65)$ \\
& Gastroesophagea 1 & $13(16.25)$ \\
& reflux & \\
& Duodenitis & $8(10)$ \\
& Peptic and duodenal & $10(12.5)$ \\
Histopathology & ulceration & \\
& Positive & $40(50)$ \\
RUT test & Negative & $40(50)$ \\
& Positive & $43(53.75)$ \\
& Negative & $37(46.25)$ \\
\hline
\end{tabular}


Ruba S. Abu-Sbeih et al. / American Journal of Biochemistry and Biotechnology 10 (1): 58-68, 2014

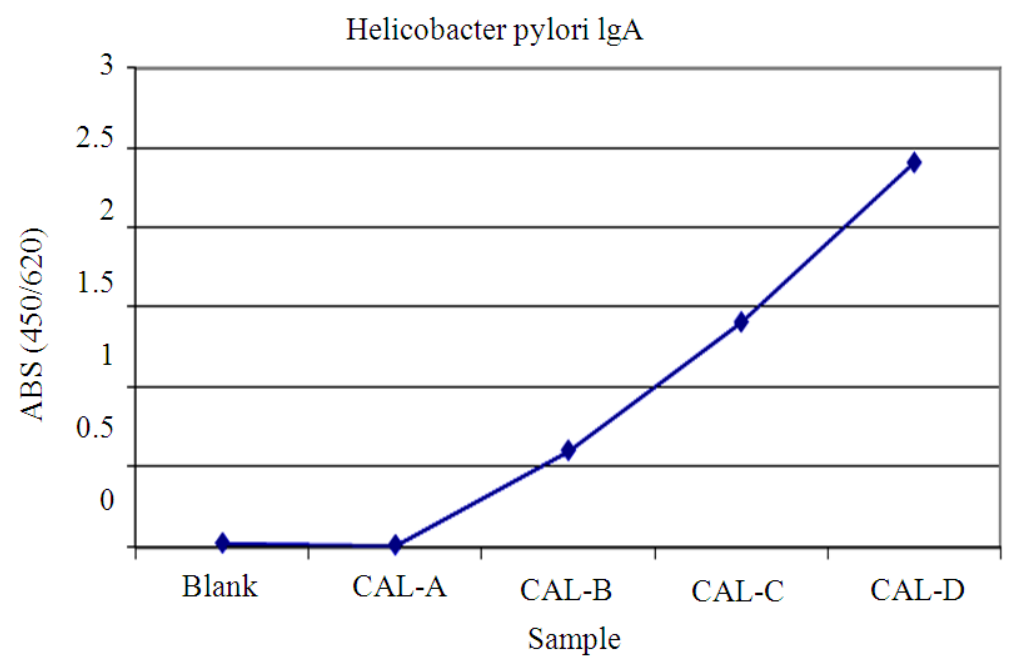

(a)

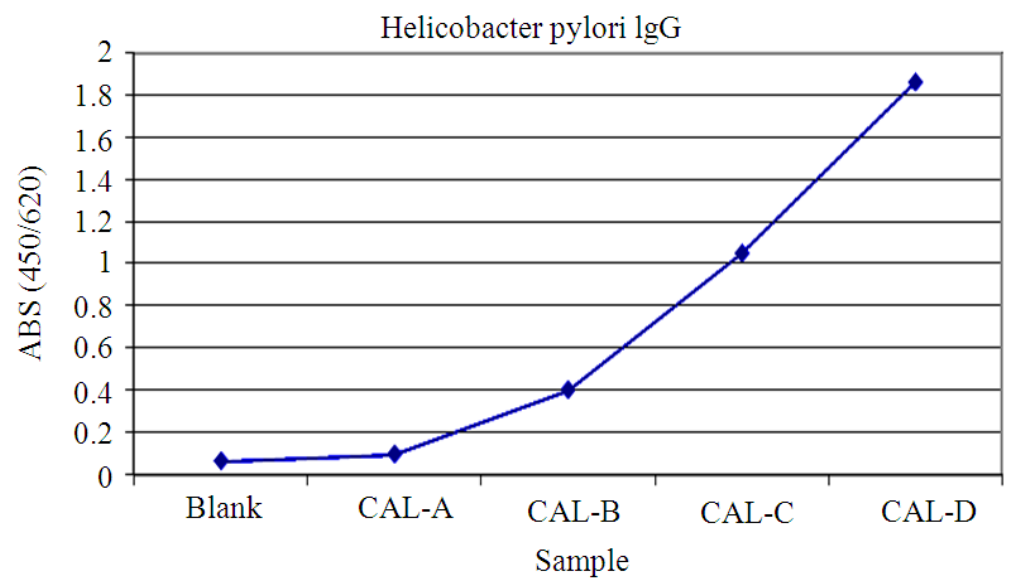

(b)

Fig. 1. The standard curve for the ELISA standard and blank solutions anti-H. pylori IgG and IgA antibody

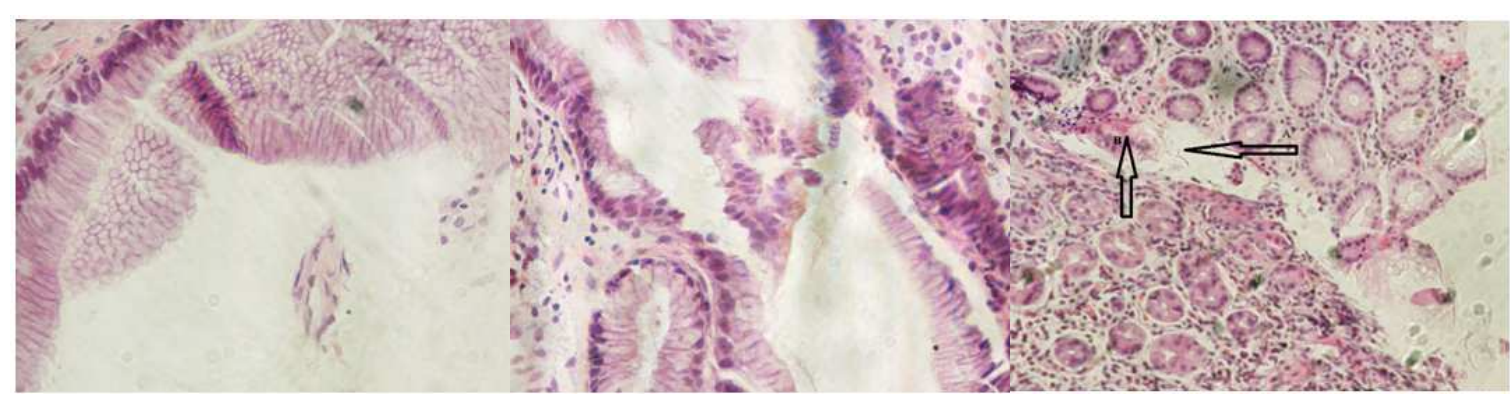

(a)

(b)

(c)

Fig. 2. Histopathology examination results (A, B) Negative hestopathological result the lumen is clear there is no bacteria and no inflammatory response (C). Positive hestopathological result showed inflammatory cells and the presence of H. pylori. The horizontal arrow indicates the presence of spiral shaped $\mathrm{H}$. pylori colonization at the lumen of the gastric tissue, while the vertical arrow showed the inflammation at the tissue (C). 


\subsection{Microscopic Examination, Oxidase, Urease and Catalase Tests}

Nineteen Helicobacter pylori isolates were obtained from the whole 80 biopsy specimen samples which cultured from the transport media on Columbia agar supplemented with selective antibiotic and $8 \%$ sheep blood, in a microaeriphilic jar for 5-7 days. The isolations were identified firstly according to colony morphology that appeared transparent almost with poor growth. Secondly, they were microscopically examined after stained with Gram stain; the isolates were Gram negative, long and spiral shape. Biochemical examinations with catalase, urease and oxidase activity were applied to all of the 19 detected bacterial colonies that are positive for H. pylori (Table 3 ). The results indicated that all of the 19 isolates were oxidase positive, transparent colonies and appeared spiral shaped under the microscopic examination.

\subsection{Antibiotic Susceptibility Test}

The $19 \mathrm{H}$. pylori positive isolates (according to the biochemical tests and gram stain) were tested for their susceptibility to 8 different types of antibiotics. The results indicated that the isolates were $100 \%$ VAncomycin (VA) and Polymyxins B (PB) resistant, 94, 84.2 and 47.4\% were resistant to AmoXicillin (AX), Kanamycin (K), Claithromycin (CLA) respectively and 84.2, 89.5 and
94.7\% were sensitive to TEtracycline (TE), TriMethoprim (TM) and RifAmpin (RA) respectively (Table 4).

\subsection{Molecular Detection of $\boldsymbol{H}$. pylori Isolates}

To confirm the results of the conventional methods that mentioned above for diagnosis of $H$. pylori (ELISA, RUT test, histopathology, culture and biochemical tests), PCR technique was used. Genomic DNA was extracted from the 19 isolates (Fig. 3) and the concentration was measured by nanodrop instrument. The extracted genomic DNA was tested to detect the presence of CagA gene in the H. pylori isolates. The CagA gene was amplified with a specific primers (5'-AATACACCAACGCCTCCAAG-3') and (5'-TTGTTGCCGCTTGCTCTC-3'). The amplified genomic DNA of the isolates produced a single PCR band of about 395 bp in size (Fig. 4). The diagnosis test results and their histopathology examination for the 19 patients are presented in Table 5.

\subsection{Statistical Analysis}

Using the statistical standard statistical equation, the sensitivity and specificity values for the $H$. pylori diagnosis test were calculated as shown in Table 6. All the tests have a high sensitivity for detection of $H$. pylori except the culture test which produced about $(47.5 \%)$ sensitivity values, where histopathology and culture tests shows $100 \%$ specificity.

Table 3. Gram stain, morphological examination and biochemical test result $(\mathrm{n}=80)$

\begin{tabular}{|c|c|c|c|c|c|c|}
\hline Tests & $\begin{array}{l}\text { Transparent } \\
\text { colonies }\end{array}$ & $\begin{array}{l}\text { Gram } \\
\text { negative }\end{array}$ & $\begin{array}{l}\text { Long and } \\
\text { spiral shaped }\end{array}$ & $\begin{array}{l}\text { Oxidase } \\
\text { positive }\end{array}$ & $\begin{array}{l}\text { Catalase } \\
\text { positive }\end{array}$ & $\begin{array}{l}\text { Urease } \\
\text { positive }\end{array}$ \\
\hline Results & $19(23.75 \%)$ & $30(37.5 \%)$ & $19(23.75 \%)$ & $19(23.75)$ & $40(50 \%)$ & $43(53.75)$ \\
\hline
\end{tabular}

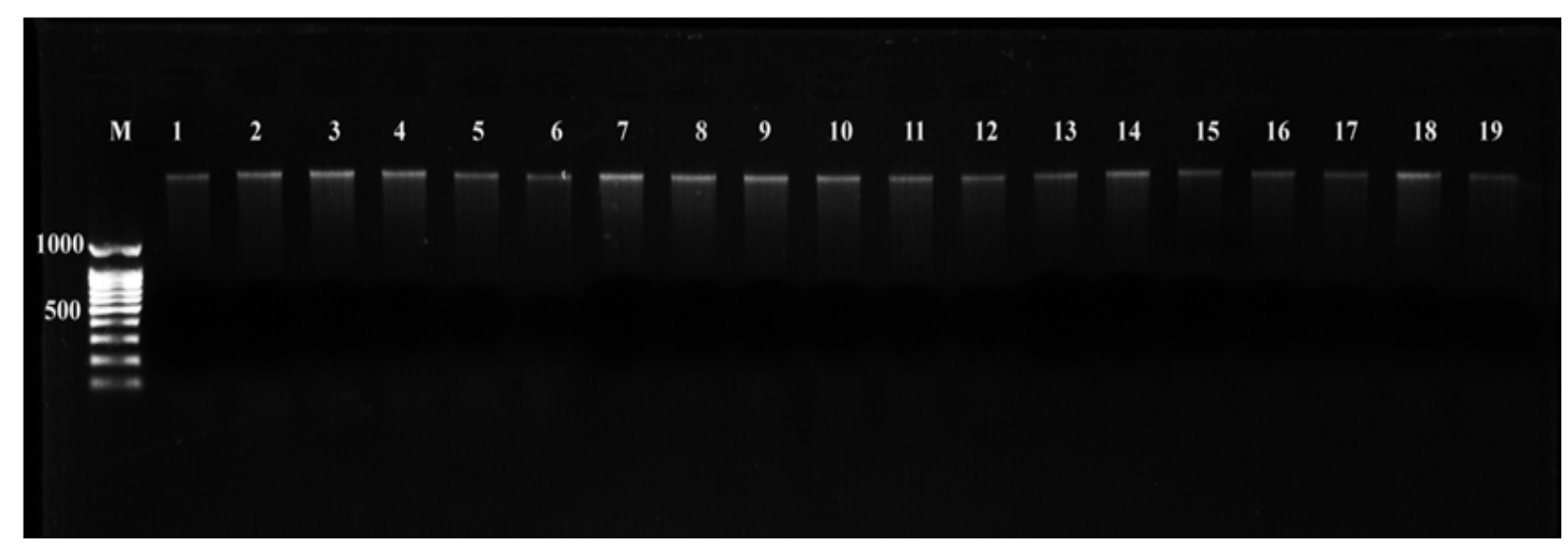

Fig. 3. Genomic DNA extraction from biopsy specimens of 19 gastric maladies patients Agarose gel (1\%) electrophoresis of genomic DNA extracted from 19 gastric biopsies, lane M: For 1 kb DNA ladder marker 


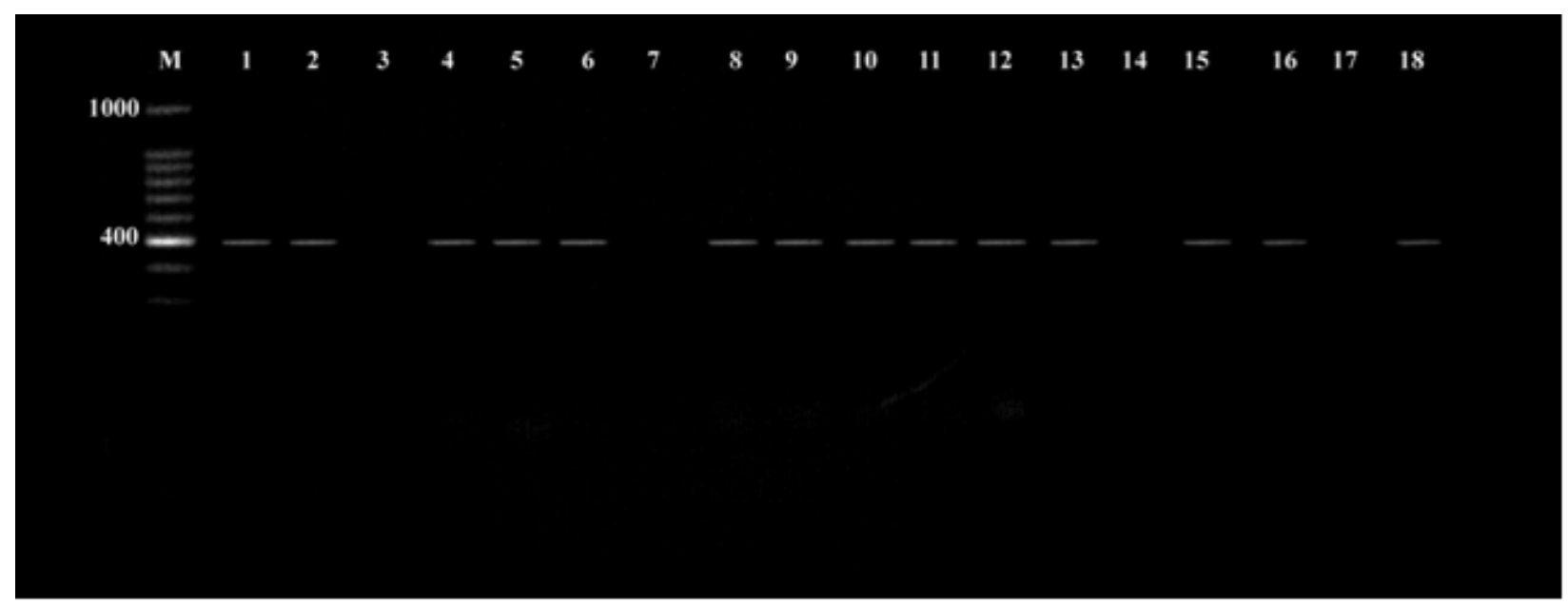

Fig. 4. The amplified CagA gene sequence for biopsy specimens. Agarose gel (1\%) electrophoresis of PCR amplification of CagA gene fragment. Lane M: For $1 \mathrm{~kb}$ DNA ladder marker

Table 4. Antibiotic susceptibility test result $(n=19)$

\begin{tabular}{lllr}
\hline Antibiotics & Resistance $(\%)$ & Intermediate $(\%)$ & Sensitive $(\%)$ \\
\hline Vancomycin, VA $(5 \mu \mathrm{g})$ & $19(100)$ & -------- & ----- \\
Polymyxins, PB $(300 \mathrm{U})$ & $19(100)$ & $-1(5.3)$ & --- \\
Amoxicillin, AX $(25 \mathrm{mcg})$ & $18(94.7)$ & ------ & $3(15.8)$ \\
Kanamycin, K $(30 \mathrm{mcg})$ & $16(84.2)$ & $1(5.3)$ & $9(47.4)$ \\
Claithromycin, CLA $(15 \mu \mathrm{g})$ & $9(47.4)$ & ----- & $16(84.2)$ \\
Tetracycline, TE $(10 \mu \mathrm{g})$ & $3(15.8)$ & ----- & $17(89.5)$ \\
Trimethoprim, TM $(2.5 \mu \mathrm{g})$ & $2(10.5)$ & ---- & $18(94.7)$ \\
Rifampin, RA $(5 \mathrm{mcg})$ & $1(5.30)$ & & \\
\hline
\end{tabular}

Table 5. Patients data and test results $(\mathrm{n}=19)$

\begin{tabular}{|c|c|c|c|c|c|c|c|c|c|c|c|}
\hline \multirow[b]{2}{*}{ No. } & \multirow[b]{2}{*}{ Sex } & \multirow[b]{2}{*}{ Age } & \multicolumn{4}{|c|}{ Biochemical test } & \multirow[b]{2}{*}{ Histo. } & \multirow[b]{2}{*}{ RUT } & \multicolumn{2}{|l|}{ ELISA* } & \multirow{2}{*}{$\begin{array}{l}\text { Endoscopic } \\
\text { examination }\end{array}$} \\
\hline & & & Culture & Oxidase & catalase & urease & & & IgA NTU/mL & IgG NTU/mL & \\
\hline 13 & $\mathrm{M}$ & 40 & + & + & + & + & + & + & $24.5+$ & $105.8+$ & H. pylori gastritis \\
\hline 15 & M & 30 & + & + & + & + & + & + & $22.4+$ & $101.7+$ & H. pylori gastritis \\
\hline 20 & $\mathrm{~F}$ & 72 & + & + & + & + & + & + & $31.1+$ & $60.8+$ & H. pylori gastritis \\
\hline 22 & M & 29 & + & + & + & + & + & + & $26.2+$ & $101.3+$ & acute duodenal ulcer \\
\hline 23 & $\mathrm{~F}$ & 37 & + & + & + & + & + & + & $33.1+$ & $62.0+$ & acute duodenal ulcer \\
\hline 24 & $\mathrm{~F}$ & 34 & + & + & + & + & + & + & $41.7+$ & $143.1+$ & Gastric ulcer \\
\hline 25 & M & 40 & + & + & + & + & + & + & $21.8+$ & $92.0+$ & Gastric ulcer \\
\hline 28 & M & 41 & + & + & + & + & + & + & $23.2+$ & $99.2+$ & Gastric ulcer \\
\hline 29 & $\mathrm{~F}$ & 30 & + & + & + & + & + & + & $27.1+$ & $25.7+$ & acute duodenal ulcer \\
\hline 32 & $\mathrm{~F}$ & 46 & + & + & + & + & + & + & $32.4+$ & $99.0+$ & Gastric ulcer \\
\hline 39 & $\mathrm{~F}$ & 52 & + & + & + & + & + & + & $27.8+$ & $130.0+$ & H. pylori gastritis \\
\hline 40 & M & 60 & + & + & + & + & + & + & $26.8+$ & $72.1+$ & H. pylori gastritis \\
\hline 45 & $\mathrm{~F}$ & 44 & + & + & + & + & + & + & $64.7+$ & $62.3+$ & Gastric ulcer \\
\hline 48 & $\mathrm{~F}$ & 48 & + & + & + & + & + & + & $16.6+$ & $46.0+$ & H. pylori gastritis \\
\hline 51 & $\mathrm{~F}$ & 30 & + & + & + & + & + & + & $21.9+$ & $98.7+$ & acute duodenal ulcer \\
\hline 57 & $\mathrm{~F}$ & 18 & + & + & + & + & + & + & $25.3+$ & $118.0+$ & acute duodenal ulcer \\
\hline 60 & $\mathrm{~F}$ & 45 & + & + & + & + & + & + & $41.8+$ & $25.7+$ & Gastric ulcer \\
\hline 79 & $\mathrm{~F}$ & 30 & + & + & + & + & + & + & $30.2+$ & $120.1+$ & Gastric ulcer \\
\hline 80 & M & 39 & + & + & + & + & + & + & $21.7+$ & $36.2+$ & H. pylori gastritis \\
\hline
\end{tabular}


Table 6. Sensitivity and specificity values for diagnostic tests of $\mathrm{H}$. pylori

\begin{tabular}{llr}
\hline The test & Sensitivity $(\%)$ & Specificity $(\%)$ \\
\hline ELISA IgG antibody & 100.0 & 60.0 \\
ELISA IgA antibody & 100.0 & 82.0 \\
Histopathology & 100.0 & 100.0 \\
RUT test & 100.0 & 93.5 \\
Culture & 47.5 & 100.0 \\
\hline
\end{tabular}

\section{DISSCUSION}

The prevalence of Helicobacter pylori differs both between and within countries, with high rates of infection being associated with low socioeconomic status and high densities of living (Goodman and Cockburn, 2001; Hazel and Francis, 2002). Approximately, 40 and $80 \%$ of adult individuals in developed and developing countries are infected respectively (Timothy and Martin, 1995). However, the percentage of infected people increases with age, since $50 \%$ of infected people were those over the age of 60 compared with around $10 \%$ between 18 and 30 years (Brown, 2000). This was not the case in this study, since the highest percentage of patients was among young people ranging from 40-60 years. In a large French cross-sectional study, a significantly lower prevalence of $H$. pylori infection was observed in females as compared with males (Broutet et al., 2001). However, in this study a highest range of infection was found among females.

The results of this study indicated that $53.75 \%$ of symptomatic patients were infected with $H$. pylori. The infection was associated with variable gastrointestinal illness, chronic gastritis, intestinal metaplasia and ulceration disease. This was in agreement with Pilotto et al. (1998) who reported that chronic superficial gastritis associated with $H$. pylori infection is a significant predisposing factor for the development of peptic ulcer, atrophic gastritis, gastric lymphoma and gastric adinocarcinoma.

Many tests are available for diagnosis of $H$. pylori infection. Invasive tests, such as culture, histopathology and biopsy urease test that are required endoscopic biopsy of gastric tissue. Non-invasive tests, such as antibody that was detected in the serum also have been used. Patients with alarming symptoms should undergo endoscopy for the diagnosis of $H$. pylori infection. When endoscopy is clinically indicated, the test of first choice is the urease test on an antral-biopsy specimen. It permits cheap and rapid detection of urease activity in the biopsy material, with a sensitivity of 79 to $100 \%$ and a specificity of 92 to $100 \%$. Sensitivity can be improved by additional biopsies, but false negative results are observed in patients with active or recent bleeding and in patients taking antibiotics or antisecretory compounds (Suerbaum and Michetti, 2002). If the urease test is negative, additional biopsy specimens stored in fixative can be sent for histological examination. Rapid urease test has been shown to be as reliable as histological examination. There were only minor differences in accuracy between the RUT and histopathology invasive tests for $H$. pylori infection in this population. RUT may be recommended as the first choice since a result is obtained within one hour (Suerbaum and Michetti, 2002).

The present study was aimed to compare the results of mostly used three invasive methods: Culture test, rapid urease test and histopathological stained based detection of $H$. pylori infection. The results of histopathology and RUT kit were almost similar, 43 $(53.75 \%)$ patients were RUT positive and $40(50 \%)$ were histology positive. The sensitivity values for these two tests were $100 \%$ to $H$. pylori, while the specificity value was found to be 93.5 for RUT and $100 \%$ for histopathology. The result of RUT is read after $60 \mathrm{~min}$ but the median positive reaction time was only $1 \mathrm{~min}$. The results of this study were in agreement with (Ricci et al., 2007) who mentioned that the sensitivity, specificity, positive predictive value, negative predictive value and accuracy were 98.2, 99, 99, 97.9 and $98.5 \%$, respectively. The sensitivity and specificity of histology for the diagnosis of $H$. pylori varies from 53 to $90 \%$, depending partly on the clinical setting, partly on the density of colonization and partly on the experience of the histopathologist.

H. pylori serologic test is cheap and widely used for the diagnosis of $H$. pylori infection in patients before treatment. Although approved laboratory-based tests have sensitivities and specificities of the commercial $H$. pylori, antibody tests seemed to vary between 60 and $100 \%$ (Salomaa et al., 2004). In this study, the result of serological test indicated that Anti-H. pylori IgG antibodies were present in $56(70 \%)$ of the samples while $47(58.75 \%)$ have IgA anti-H. pylori antibodies. Specificity and sensitivity for IgG were 60 and 100 and were 80 and $100 \%$ for IgA, respectively. The results of this study indicated that the accuracy of the $H$. pylori $\mathrm{IgG}$ and $\operatorname{IgA}$ tests were in agreement with the previous reference. The accuracy of serological tests is strongly dependent on the prevalence of $H$. pylori infection. Although it has been recommended that antibody assays be evaluated locally, this has rarely been carried out for different age groups. To avoid any misjudgment in the validation of serological tests for $H$. pylori antibodies in adult subjects, the validation should be carried out 
separately for different age groups with special emphasis not only on the known $H$. pylori status but also on the presence of atrophic gastritis (Salomaa et al., 2004).

Primary isolation of $H$. pylori from a biopsy specimen is a difficult process. Several factors, which are difficult to control, cause difficulty with the culturing of this bacterium. Another study showed that the percentage of culture positive specimen was $31.94 \%$ (Kagar et al., 2011). Patchy distribution of the organism on the gastric mucosa, contamination of biopsy forceps, presence of oropharangyeal flora, loss of viability of the organism during transportation, all these may be responsible for a poor negative predictive value associated with culture of H. pylori (Meunier et al., 1997). Culture of H. pylori with antibiotic-sensitivity testing is not routinely performed for the initial diagnosis of $H$. pylori infection, but it is recommended after the failure of second-line therapy (Bazzoli, 2001). Guidelines for performing antibioticsusceptibility tests of $H$. pylori have been developed by the National Committee for Clinical Laboratory Standards (Performance standards for antimicrobial susceptibility testing, 1999). In this study, the rate of isolation of $H$. pylori from the antral biopsy specimens were $47.5 \%$ and the sensitivity and specificity of this test were $47.5,100 \%$ respectively. This is in agreement with Ricci et al. (2007) who indicated that culture test has a high specificity $(100 \%)$ and the sensitivity is often lower.

Bacterial contamination of the medium was frequent. The contaminant bacteria were Pseudomonas spp., Proteus spp. and Klebsiella spp., the source of which could be contaminated biopsy forceps and contamination during obtaining, transporting and preparing of the defibrinated sheep blood added to the classic Columbia agar. The growth rate of $H$. pylori on this medium was slow, as 5 to 7 days were needed for the colonies to appear. Columbia blood agar is a nonselective medium used for many years alone or in combination with other non-selective and selective media for culturing $H$. pylori from antral biopsy specimens taken from peptic ulcer patients during upper gastrointestinal endoscopy (Fresnadillo Martinez et al., 1997). The isolation rate of $H$. pylori using this medium alone is very variable. Results as low as only $28.5 \%$ total isolation rate were reported by some authors (Piccolomini et al., 1997).

PCR has been used extensively for the diagnosis of H. pylori from gastric biopsy specimens, saliva, faeces and archival specimens, as well as for detecting clarithromycin resistance (Ricci et al., 2007). The targets of these PCR methods included urease A (ureA) gene cag A gene, phosphosamine mutase (glmM) gene and 23S rRNA gene (Tomatari et al., 2010). In this study,
PCR technique was used to determine the virulence factor CagA in H. pylori; $73.6 \%$ of the biopsy specimens were CagA positive. Smith et al. (2011) and his colleagues detected $H$. pylori in $35 \%$ of their patients using a PCR method in Nigeria.

The disadvantages of PCR as a routine test are that it is a technically demanding and expensive test compared to culture, histology and the rapid urease tests. It requires special laboratory conditions with separate facilities for each stage of the technique and as it is highly sensitive, it is subject to false-positive results by contamination. A positive result detected by any of the molecular techniques does not only indicate current infection but will also detect the DNA or dead organisms (Lisby, 1999). Molecular biology is useful in the study of pathogenicity and immunization vis-à-vis Helicobacter pylori. The recent description of the genome of $H$. pylori causes molecular biology at the forefront in research on $H$. pylori. PCR is considered the most sensitive method for the detection of microorganisms. This would make the test particularly useful in the evaluation of eradication. Other indications include the detection of $H$. pylori outside the stomach, although $H$. pylori is present in small numbers among many other microorganisms causing false positive in other tests based on urease and culture (Hassina and Ahmed, 2013).

Antibiotic resistance has increasingly been recognized as a major cause of treatment failure for $H$. pylori infection. Primary antimicrobial resistance against clarithromycin and metronidazole is now commonplace in several countries (Poon et al., 2002). Regional variations in susceptibility and resistance patterns may be ascribed to differences in local antibiotic prescription practices, antibiotic usage in the community and mass eradication programs for $H$. pylori infection as part of gastric cancer prevention strategies. These factors may well be expected to influence success of eradication therapy (Wong et al., 2002). In this study, all the 19 isolated strains showed various degree of sensitivity to all the first line of antibiotics namely trimethoprim, rifampin, clarithromycin, kanamycin and tetracycline. The results indicated that the isolates were $100 \%$ vancomycin and polymyxins B resistant and 94\%, amoxicillin resistant.

\section{ACKNOWLEDGMENT}

The researchers are expressing their appreciations to Al-Balqa' Applied University for the financial support of this study. 


\section{REFERENCES}

Abdalsadeg, N.A.O., A.A. Adam, H. Abdul-Aziz, W.H. Omer and H.A. Osman et al., 2012. Comparison of different diagnostic methods of helicobacter pylori infection in Sudanese patients. Al Neelain Med. J.

Al-Sulami, A.A., A.M. Al-Taee and M.G. Juma'a, 2010. Isolation and identification of helicobacter pylori from drinking water in Basra governorate, Iraq. East. Mediterr. Health J., 16: 920-925. PMID: 21218716

Balows, A., W.J. Hausler, K.L. Jr., Herrmann, H.D. Isenberg and H.J. Shadomy, 1991. Manual of Clinical Microbiology. 5th Edn., American Society for Microbiology, Washington, D.C., ISBN-10: 1555810292 , pp: 1364.

Bazzoli, F., 2001. Key points from the revised maastricht consensus report: The impact on general practice. Eur. J. Gastroenterol. Hepatol., 13: S3-S7. PMID: 11686230

Bazzoli, F., M. Zagari, S. Fossi, P. Pozzato and L. Ricciardiello et al., 1997. Urea breath tests for the detection of helicobacter pylori infection. Helicobacter, 2: 34-37. DOI: 10.1111/j.1523-5378.1997.06b10.x

Broutet, N., A.M. Sarasqueta, C. Sakarovitch, F. Cantet and D. Lethuaire et al., 2001. Helicobacter pylori infection in patients consulting gastroenterologists in france: Prevalence is linked to gender and region of residence. Eur. J. Gastroenterol. Hepatol., 13: 677684. DOI: $10.1097 / 00042737-200106000-00011$

Brown, L.M., 2000. Helicobacter pylori epidemiology and routes of transmission. Epidemiol. Rev., 22: 283-297.

DOI: 10.1093/oxfordjournals.epirev.a018040

Cogo, L.L., C.L. B. Monteiro, K.D.S. Nogueira, J.K. Palmeiro and M.L. Ribeiro et al., 2011. Characterization of virulence genes caga and vaca in helicobacter pylori and their prevalence in gastrointestinal disorders. Braz. J. Microbiol., 42: 1289-1295. DOI:

$10.1590 / \mathrm{S} 1517-$ 83822011000400007

Dixon, M.F., R.M. Genta and J.H. Yardley, 1996. Classification and grading: The updated sydney system. Proceedings of the International Workshop Histopathology Gastritis, (WHG' 96), Houston, pp: 1161-1181. DOI: 10.1097/00000478-199610000-00001

Fresnadillo Martinez, M.J., M. Rodriguez Rincon, A.M. Blazquez De Castro, E. Garcia Sanchez and J.E. Garcia Sanchez et al., 1997. Comparative evaluation of selective and nonselective media for primary isolation of helicobacter pylori from gastric biopsies. Helicobacter, 2: 36-39. DOI: 10.1111/j.1523-5378.1997.tb00055.x
Goodman, K.J. and M. Cockburn, 2001. The role of epidemiology in understanding the health effects of helicobacter pylori. Epidemiol., 12: 266-271. DOI: 10.1097/00001648-200103000-00023

Hassina, G. and B. Ahmed, 2013. Isolation and characterization of helicobacter pylori strains from gastric biopsies of Algerian patients. Online J. Biol. Sci., 13: 41-49. DOI: 10.3844/ojbsci.2013.41.49

Hazel, M. and M. Francis, 2002. Epidemiology and diagnosis of $H$. pylori infection. Helicobacter, 7: 816. DOI: 10.1046/j.1523-5378.7.s1.10.x

Kagar, M., M. Bagdernejad, A. Doosti and S.G. Daliani, 2011. Clarithromycin resistance and 23S rRNA mutations in Helicobacter pylori isolates in Iran. Afr. J. Microbiol. Res., 5: 853-850.

Lisby, G., 1999. A pplication of nucleic acid amplification to clinical microbiology. Mol. Biotechnol., 12: 75-99. PMID: 10554773

MacFaddin, J.F., 2000. Biochemical Tests for Identification of Medical Bacteria. 3rd Edn. Lippincott Williams and Wilkins, ISBN-10: 0683053183, pp: 912.

Megraud, F. and P. Lehours, 2007. Helicobacter pylori detection and antimicrobial susceptibility testing. Clinical Microbiol. Rev. Rev., 20: 280-322. PMID: 17428887

Meunier, O., P. Walter, P. Chamouard, Y. Piemont and H. Monteil, 1997. Isolation of helicobacter pylori: Necessity of control of transport conditions. Pathologie-Biologie, 45: 82-85. PMID: 9097852

Montecucco, C. and R. Rappuoli, 2001. Living dangerously: How helicobacter pylori survives in the human stomach. Nat. Rev. Mol. Cell Biol., 2: 457-466. PMID: 11389469

Morris, A.J., M.R. Ali, G.I. Nicholson, G.I. Perez-Perez and M.J. Blaser, 1991. Long-term follow-up of voluntary ingestion of helicobacter pylori. Ann. Intern. Med., 114: 662-663. DOI: 10.7326/0003-4819-114-8-662

Ottemann, K.M. and A. Lowenthal, 2002. Helicobacter pylori uses motility for both initial colonization and to attain robust infection. Infect. Immun., 70: 19841990. DOI: 10.1128/IAI.70.4.1984-1990.2002

Piccolomini, R., G. Di Bonaventura, D. Festi, G. Catamo and F. Laterza et al., 1997. Optimal combination of media for primary isolation of Helicobacter pylori from gastric biopsy specimens. J. Clin. Microbiol., 35: 1541-1544. PMCID: PMC229783

Pilotto, A., M. Franceschi, F. Di Mario, G. Leandro and L. Bozzola et al., 1998. The long-term clinical outcome of elderly patients with helicobacter pyloriassociated peptic ulcer disease. Gerontology, 44: 153-158. DOI: $10.1159 / 000022000$ 
Poon, S.K., C.S. Chang, J. Su, C.H. Lai and C.C. Yang et al., 2002. Primary resistance to antibiotics and its clinical impact on the efficacy of helicobacter pylori lansoprazole-based triple therapies. Aliment. Pharmacol. Ther., 16: 291-296. DOI: 10.1046/j.1365-2036.2002.01184.x

Ricci, C., J. Holton and D. Vaira, 2007. Diagnosis of helicobacter pylori: Invasive and non-invasive tests. Best Practice Res. Clin. Gastroenterol., 2: 299-313. DOI: 10.1016/j.bpg.2006.11.002

Salomaa, R.A., T.U. Kosunen, J. Mattila, S. Sarna and H. Rautlin, 2004. Age-dependent accuracy of helicobacter pylori antibody assays for adults, with special emphasis on atrophic gastritis. Clin. Diagn. Lab. Immunol., 11: 1185-1188. DOI: 10.1128/CDLI.11.6.1185-1188.2004

Smith, S., M.A. Fowora, J.A. Otegbayo, F.B. Abdulkareem and E.A. Omonigbehin et al., 2011. Comparison of PCR with other diagnostic techniques for the detection of $H$. pylori infection in patients presenting with gastroduodenal symptons in Nigeria. Int. J. Mol. Epidemiol. Genet., 2:178-184. PMCID: PMC3110392

Suerbaum, S. and P. Michetti, 2002. Helicobacter pylori infection. N. Engl. J. Med., 347: 1175-1186. DOI: 10.1056/NEJMra020542

Timothy, L.C. and J.B. Martin, 1995. Helicobacter pylori a bacterial cause of gastritis, peptic ulcer disease and gastric cancer. Features, 61: 21-26.

Tiwari, S.K., A.A. Khan, K.S. Ahmed, I. Ahmed and F. Kauser et al., 2005. Rapid diagnosis of helicobacter pylori infection in dyspeptic patients using salivary secretion: A non-invasive approach. Singapore Med. J., 46: 224-228. PMID: 15858691
Tomatari, F.H., A.M. Mobarez, M. Amini, D. Hosseini and A. Talebi et al., 2010. Helicobacter pylori resistance to metronidazole and clarithromycin in dyspeptic patients in Iran. IRCMJ, 12: 409-412.

Vaira, D. and N. Vakil, 2001. Blood, urine, stool, breath, money and helicobacter pylori. Gut., 48: 287-289. DOI: 10.1136/gut.48.3.287

Vinette, K.M.B., K.M. Gibney, R. Proujansky and P.T. Fawcett, 2002. Growth of helicobacter pylori in a long spiral form does not alter expression of immunodominant proteins. BMC Microbiol., 2: 124. DOI: $10.1186 / 1471-2180-2-24$

Wong, W.M., B.C. Wong, H. Lu, Q. Gu and Y. Yin et al., 2002. One-week omeprazole, furazolidone and amoxicillin rescue therapy after failure of Helicobacter pylori eradication with standard triple therapies. Aliment. Pharmacol. Ther., 16: 793-798. DOI: 10.1046/j.1365-2036.2002.01223.X

Yoshida, H., K. Hirota, Y. Shiratori, T. Nihei and S. Amano et al., 1998. Use of a gastric juice-based pcr assay to detect helicobacter pylori infection in culture-negative patients. J. Clin. Microbiol., 36: 317-320.

Zagari, R.M., F. Bazzoli, P. Pozzato, S. Fossi and L. De Luca et al., 1999. Review article: Noninvasive methods for the diagnosis of helicobacter pylori infection. Ital. J. Gastroenterol. Hepatol., 31: 408-15.

Zsikla, V., S. Hailemariam and M. Baumann, 2006. Increased rate of helicobacter pylori infection detected by PCR in biopsies with chronic gastritis. Am. J. Surg. Pathol., 30: 242-248. DOI: 10.1097/01.pas.0000186397.18206.1b 